\title{
Criatividade, Dança e Psicanálise: Uma Revisão Sistemática
}

\author{
Raphael Edson Dutra
}

Maíra Bonafé Sei

\section{RESUMO}

0 presente trabalho se organiza como uma revisão sistemática que visa mapear as publicações de investigações psicanalíticas indexadas em bases de dados referente ao tema criatividade articulado à dança. Elegeu-se as bases de dados SciELO, PePSIC, PsycInfo, LILACS, BVS, CLASE, Web of Science e Scopus e aplicou-se os critérios de inclusão e exclusão no material encontrado. No levantamento inicial, foram encontrados 114 registros de textos disponíveis; destes, retirou-se os duplos e os que não atenderam aos critérios, formando o banco de dados final com oito textos. Aglomerou-se os textos selecionados em duas categorias de análise sendo elas: Criatividade, Dança e Psicoterapia; Criatividade, Dança e Dinâmica Psíquica. 0 trabalho conclui que, apesar da criatividade ser tema recorrente na psicanálise, há uma baixa produção no que se refere à dança, o que indica que estudos com esse alvo de investigação carecem ser realizados.

Palavras-chave: Psicanálise; Criatividade; Dança.

\section{ABSTRACT}

\section{Creativity, Dance and Psychoanalysis: A Systematic Review}

The present work is organized as a systematic review that aims to map the publications of psychoanalytic investigations indexed in databases related to the theme of creativity linked to dance. The databases SciELO, PePSIC, PsycINFO, LILACS, BVS, CLASS, Web of Science, and Scopus, were selected, and inclusion and exclusion criteria were applied to the material found. In the initial survey, 114 records of available texts were found, of which the duplicates and those that did not meet the criteria were removed, forming the final database with eight texts. The selected texts were agglomerated into two categories of analysis: Creativity, Dance, and Psychotherapy; Creativity, Dance, and Psychic Dynamics. The study concludes that, although creativity is a recurring theme in psychoanalysis, there is a low production in dance, which indicates that studies with this research target need to be performed.

Keywords: Psychoanalysis; Creativity; Dance.

\section{INTRODUÇÃO}

Criatividade e Psicanálise possuem uma estreita relação, sendo alvo de investigação e pressuposições teóricas de autores como Winnicott, que dedicou parte de sua obra a tratar o tema com maiores detalhes, desenvolvendo teses a respeito da dinâmica psíquica imbricada nesse processo. Por meio da criatividade, expressões humanas tomam forma e manifestam estados intelectuais e artísticos que moldam a realidade na qual vivemos, compreendendo-se que no criar nos desenvolvemos como humanos e civilização. Nesse sentido, é pela via da criatividade que "o indivíduo sente que a vida é digna de ser vivida" (Winnicott, 1975, p.95), com a criatividade desempenhando um papel fundamental para o curso de um estado emocional saudável (Winnicott, 1975).

\section{Sobre os autores}

R. E. D.

http://orcid.org/0000-00024689-4842

Universidade Estadual de Londrina - Londrina, PR raphaeledson15@gmail.com

M. B. S

http://orcid.org/0000-00030693-5029

Universidade Estadual de

Londrina - Londrina, PR

mairabonafe@gmail.com

\section{Direitos Autorais}

Este é um artigo de acesso aberto e pode ser reproduzido livremente, distribuído, transmitido ou modificado, por qualquer pessoa desde que usado sem fins comerciais. 0 trabalho é disponibilizado sob a licença Creative Commons CC-BY-NC.

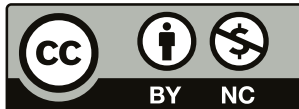




\section{H. INTERACÃO EM L PSICOLOGIA}

Nesse sentido, apesar de Winnicott (1975) afirmar que podemos encontrar o impulso criativo em qualquer pessoa, e em suas atividades, pois trata-se de uma maneira saudável de realizar algo, concordamos com o autor ao propor que podemos evidenciar esse processo nas produções artísticas. Assim, incluída como uma produção da cultura e inscrita no arsenal artístico da humanidade, a dança, como arte gestual ritmada, permite que seus bailarinos e dançarinos, em tese, manifestem sua criatividade, e os elementos afetivos que nela estão atrelados, em suas obras e no modo de vivenciá-la. Com isso, na dança o artista rememora um tempo intersubjetivo no qual a palavra ainda não está presente, encontrando dados de significação expressos no movimento e no corpo (Victoriano, 2011). Nesse arranjo, como no brincar, no sentido winnicottiano, dança e representações criativas do corpo "estreitam-se num pas de deux de infinitos arranjos" (Campos, 2011, p. 26).

Dessa forma, propomos investigar o estado das publicações em psicanálise referentes ao tema e no que concerne à prática artística da dança, visando compreender, nesta revisão, como os autores da área fazem referência e tratam o tema em suas investigações.

\section{MÉTODO}

Para a realização deste estudo, utilizou-se como base metodológica a revisão sistemática, a qual busca potencializar e aumentar, de modo exponencial e qualitativamente, a busca de resultados, encontrando-os de forma organizada e maximizada (Costa \& Zoltowski, 2014). Segundo Galvão e Pereira (2014), ao se deparar com o tema de pesquisa, frequentemente, o pesquisador encontra no percurso da investigação resultados que podem apresentar-se de modo contraditório. Dessa forma, a revisão de literatura sistemática atua em um sentido coerente na tentativa de esclarecimento da temática, tomando como apoio uma revisão com enfoque bem definido ao "identificar, selecionar, avaliar e sintetizar as evidências relevantes disponíveis" (Galvão \& Pereira, 2014, p. 183). Portanto, a revisão sistemática configura-se como um procedimento metodológico no qual se visa incorporar as "informações de um conjunto de estudos realizados separadamente sobre determinada terapêutica/intervenção, que podem apresentar resultados conflitantes e/ou coincidentes, bem como identificar temas que necessitam de evidência" (Sampaio \& Mancini, 2007, p. 84).

Para a construção do artigo, tomamos como base os procedimentos prático-metodológicos apresentados por Costa e Zoltowski (2014), por meio dos seguintes passos: 1) Delineamento da questão a ser pesquisada; 2) Eleição de fontes de dados a serem utilizadas; 3) Escolha das palavras-chave que se adequem à busca; 4) Armazenamento do material coletado; 5) Aplicação dos critérios de inclusão e exclusão aos resu- mos dos artigos; 6) Extração do material coletado; 7) Avaliação dos textos selecionados; 8) Apresentação e interpretação dos dados.

A questão norteadora para esta investigação apresentou-se como "O que foi produzido pela comunidade científica nacional e internacional a respeito do tema criatividade e psicanálise articulado à dança?". A partir dessa, foram eleitas as bases de dados SciELO, PePSIC, PsycInfo, LILACS, BVS, CLA$\mathrm{SE}$, Web of Science e Scopus, extraindo e armazenando destes os relatórios com os resumos dos textos potencialmente relevantes. As palavras-chave selecionadas para a busca foram as combinações "Criatividade AND Ballet OR Dança AND Psicanálise" para português, e "Creativity AND Ballet OR Dance AND Psychoanalysis" para a busca em inglês. Delimitou-se como critérios de inclusão os textos que focalizam estudos de caso, investigações teóricas ou pesquisas de campo de natureza qualitativa que se referem à temática criatividade e dança, tratando e analisando os dados por meio da abordagem psicanalítica. No que tange aos critérios de exclusão, foram retirados do banco de dados final textos de base não psicanalítica; artigos que não estavam dentro do escopo da Psicologia; publicações em formatos que não fossem artigos em base de dados, tais como dissertações, teses, livros, ensaios, comentários ao editor, resenhas, resumos de teses e dissertações, etc.; investigações de cunho quantitativo que não tivessem interface com a psicanálise ou de teorias que se apoiam nela. A busca procurou mapear os artigos publicados no período fixo de 2007 a 2018.

\section{RESULTADOS}

Baseando-se nas palavras-chave e nos critérios de inclusão e exclusão adotados, foi possível encontrar 115 registros de artigos indexados às bases de dados, com potencial relevância para a temática que nos propusemos investigar. Após o levantamento geral dos possíveis materiais a serem utilizados, foram excluídos os títulos duplicados, totalizando 29 exclusões.

$\mathrm{Na}$ aplicação dos critérios de inclusão e exclusão, foram retirados 76 itens que não se enquadraram no delineamento da pesquisa. Portanto, compôs-se para o banco de dados final 10 artigos a serem utilizados no referencial da investigação. Os dados do processo de coleta de dados estão expostos na figura 1 abaixo. 


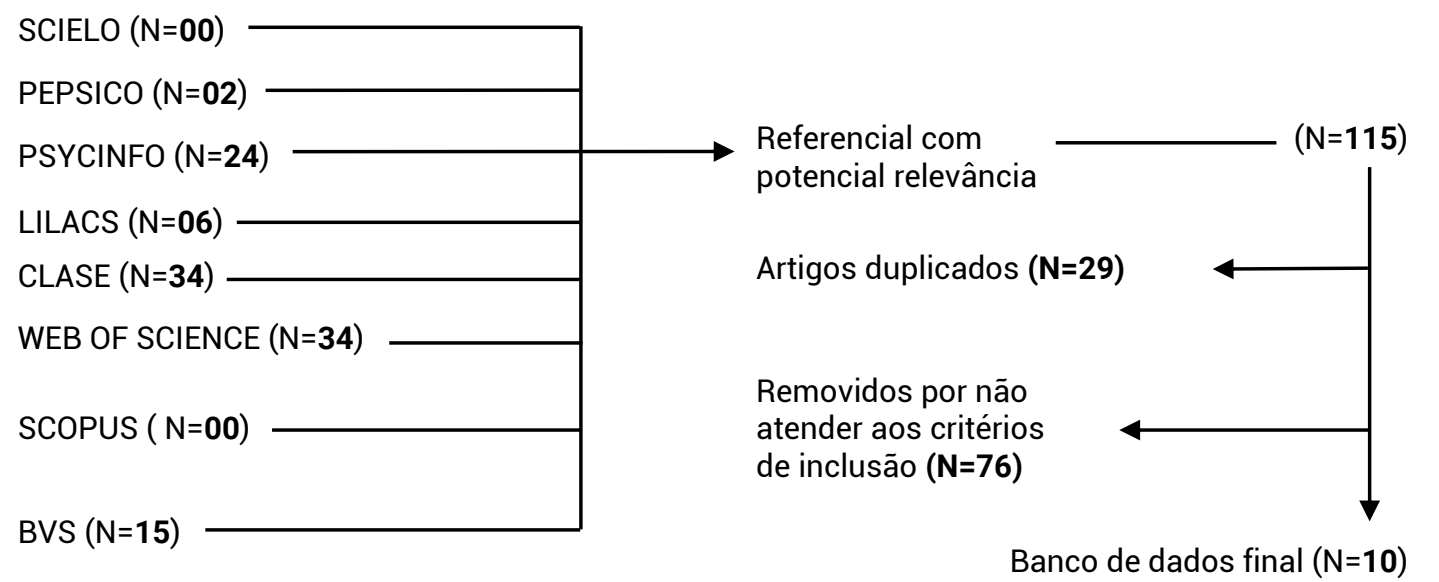

Figura 1. Processo De Coleta De Dados

Fonte: Autor.

0 resultado da coleta de dados foi composto, predominantemente, por artigos publicados em inglês, cerca de seis registros, em oposição ao material em língua portuguesa, que contou com três registros, o que indica baixa produção nacional em relação à temática. Buscou-se contemplar também as publicações da América Latina e, embora tenham sido encontrados seis artigos disponíveis, seus delineamentos não eram compatíveis com os critérios utilizados para a avaliação enquadrando-se, em sua maioria, na discussão da relação das danças mexicanas e argentinas articuladas com as produções da cultura e das construções sociais, tomando como base teorias não psicológicas, excedendo os limites deste estudo.

De modo a facilitar a apresentação dos dados encontrados, bem como extrair os elementos pertinentes aos respectivos delineamentos, organizou-se o material em categorias iniciais (pré-categorias), conforme aponta a tabela 1.

A partir do material coletado, é possível perceber a baixa produção e investigação científica em torno da temática, sendo ausente entre os anos de 2007-2008, 2013-2014. Dessa forma, a pesquisa aclarou a majoritariedade de pesquisas de base qualitativa que se apoiam em metodologia de cunho bibliográfico, articulando a teoria a algum tipo de produção da cultura, por exemplo, um filme. No que tange ao referencial teórico abordado, tem-se a prevalência de autores de língua inglesa, como Winnicott, Klein e Bion, da psicologia do self, como Heinz Kohut, e também representantes da psicanálise francesa, como Lacan, e da psicanálise freudiana. Ao investigar a criatividade aplicada à dança, os autores selecionados atém-se tanto para o setting clínico, com enfoque psicoterapêutico, como à dinâmica da linguagem expressiva criativa presente na dança.

\section{DISCUSSÃO}

A partir do material coletado, estabeleceu-se duas categorias de análise de momentos pelos quais o tema é abordado nos textos, agrupando-os de modo a dar-lhe coesão e ampliando a compreensão do tema. São elas: Criatividade, Dança e Psicoterapia; Criatividade, Dança e Dinâmica Psíquica. Para a categorização dos registros coletados, levou-se em consideração a compreensão da abordagem ao tema e os caminhos em que foram articuladas à dança. Nesse processo, aglomerou-se os textos em temas que, por similaridade, tratam do assunto de modo (caminho) equivalente. Elegeu-se, nesse contexto, a interface da criatividade e da dança com a psicoterapia, tomando-a como elemento presente nas intervenções do processo saúde/doença; e, por outro lado, aqueles que, mediados pelo arsenal de conceitos da psicanálise, aplicam seu conhecimento à dança e associam as produções criativas às suas descobertas.

\section{CRIATIVIDADE, DANÇA E PSICOTERAPIA}

Uma das possibilidades para se compreender a interface criatividade e dança apontada pelos autores, concerne à sua utilização como método psicoterapêutico apoiado na psicanálise como estratégia de intervenção. Nesse sentido, o trabalho de Valdivia (2010) apresenta um modelo psicoterápico, a "Dance Movement Psychotherapy", que embasada, nesse caso, nos constructos teóricos de Winnicott sobre a criatividade, articula-se ao processo saúde-doença, estabelecendo uma ponte entre o brincar e o movimento dos corpos à expressão na dança. 
Tabela 1. Categorias Iniciais

\begin{tabular}{|c|c|c|c|}
\hline Título & Ano & Objetivos & Referencial Teórico \\
\hline $\begin{array}{l}\text { Self psychology and the } \\
\text { modern dance choreographer }\end{array}$ & 2009 & $\begin{array}{l}\text { Investigar a importância da criatividade, da arte e da } \\
\text { estética na saúde mental no cotidiano, por meio da } \\
\text { articulação de experiências de coreógrafos da dança } \\
\text { moderna com a psicologia do self. }\end{array}$ & $\begin{array}{l}\text { Psicanálise, autor } \\
\text { consultado: Heinz } \\
\text { Kohut. }\end{array}$ \\
\hline $\begin{array}{l}\text { A dança "en-cena" o Outro: } \\
\text { prerrogativas para uma } \\
\text { educação estética por meio do } \\
\text { processo criativo }\end{array}$ & 2009 & $\begin{array}{l}\text { Entender o processo criativo como campo de } \\
\text { sensibilização corporal, no qual a educação criativa } \\
\text { pode ser efetiva no corpo. }\end{array}$ & $\begin{array}{l}\text { Filosofia e Psicanálise, } \\
\text { autor consultado: } \\
\text { Lacan. }\end{array}$ \\
\hline $\begin{array}{l}\text { A psychoanalytic perspective of } \\
\text { endings in therapy: A dance } \\
\text { movement psychotherapy case } \\
\text { study }\end{array}$ & 2010 & $\begin{array}{l}\text { Descrever um relato de uma psicoterapia embasada } \\
\text { no movimento de dança em um paciente de nove } \\
\text { anos. }\end{array}$ & $\begin{array}{l}\text { Psicanálise, autor } \\
\text { consultado: D. } \\
\text { Winnicott e Klein }\end{array}$ \\
\hline $\begin{array}{l}\text { Psychodynamic Movement and } \\
\text { Dance Therapy (PMDT) in } \\
\text { Hungary }\end{array}$ & 2012 & $\begin{array}{l}\text { Apresentar a perspectiva do Movimento } \\
\text { Psicodinâmico e a Terapia de Dança como método } \\
\text { psicoterápico de orientação psicanalítica. }\end{array}$ & $\begin{array}{l}\text { Psicanálise, autores } \\
\text { consultados: Winnicott, } \\
\text { Bion e Ferenczi. }\end{array}$ \\
\hline $\begin{array}{l}\text { Vaslav Nijinsky, una mirada } \\
\text { psicoanalítica sobre su arte y } \\
\text { su locura }\end{array}$ & 2012 & $\begin{array}{l}\text { Articular o ato criativo do bailarino e coreógrafo russo } \\
\text { Vaslav Nijinsky com os conceitos de Lacan. }\end{array}$ & $\begin{array}{l}\text { Psicanálise, autores } \\
\text { consultados: Lacan. }\end{array}$ \\
\hline $\begin{array}{l}0 \text { balanceamento entre as } \\
\text { posições esquizo-paranoide e } \\
\text { depressiva ( } P s \leftrightarrow d) \text { na } \\
\text { psicodinâmica criativa }\end{array}$ & 2015 & $\begin{array}{l}\text { Apresentar a pertinência da aplicação do modelo de } \\
\text { Bion na interlocução entre as posições esquizo- } \\
\text { paranoide e depressiva (PS↔D), ao processo criativo } \\
\text { artístico do teatro, pintura, da literatura e da dança } \\
\text { moderna. }\end{array}$ & $\begin{array}{l}\text { Psicanálise, autor } \\
\text { consultado: Bion. }\end{array}$ \\
\hline $\begin{array}{l}\text { Listening to All of You with All } \\
\text { of Me: The Arts, Empathy, and } \\
\text { the Analyst }\end{array}$ & 2016 & $\begin{array}{l}\text { Apresentar como a psicanálise contemporânea, } \\
\text { embasada no conceito de "empathy", pode expandir a } \\
\text { capacidade clínica por meio de formas criativas na } \\
\text { escuta e na resposta, articulando a psicanálise e } \\
\text { autores da dança. }\end{array}$ & $\begin{array}{l}\text { Psicanálise, autor } \\
\text { consultado: Heinz } \\
\text { Kohut. }\end{array}$ \\
\hline $\begin{array}{l}\text { The Red Shoes: A Fairy Tale } \\
\text { Within a Ballet Within a Film }\end{array}$ & 2016 & $\begin{array}{l}\text { Discutir, a partir da temática de ballet presente no } \\
\text { filme The Red Shoes, as maneiras como uma } \\
\text { compulsão para criar pode levar a um aprimoramento, } \\
\text { mas também a uma ferida no eu, nas fronteiras da } \\
\text { criatividade, Eros e morte. }\end{array}$ & $\begin{array}{l}\text { Psicanálise, autores } \\
\text { consultados: Freud e } \\
\text { Heinz Kohut. }\end{array}$ \\
\hline $\begin{array}{l}\text { Um Olhar Psicanalítico Sobre } 0 \\
\text { Uso Das Danças Circulares } \\
\text { Como Instrumento De Trabalho } \\
\text { Com Grupos }\end{array}$ & 2017 & $\begin{array}{l}\text { Propor uma análise psicanalítica de grupo para a } \\
\text { utilização das Danças Circulares com instrumento de } \\
\text { analistas. }\end{array}$ & $\begin{array}{l}\text { Psicanálise, autores } \\
\text { consultados: Winnicott } \\
\text { e Bion. }\end{array}$ \\
\hline $\begin{array}{l}\text { Therapeutic action and } \\
\text { aesthetic experience: } \\
\text { Resonance and reorganization }\end{array}$ & 2018 & $\begin{array}{l}\text { Analisar como a dança pode servir como uma ponte } \\
\text { para expressão do artista e do observador, e, por meio } \\
\text { da linguagem, reorganizar ideias e favorecer o processo } \\
\text { de criar, mesmo que o conteúdo seja doloroso. }\end{array}$ & $\begin{array}{l}\text { Psicanálise, autor } \\
\text { consultado: Freud. }\end{array}$ \\
\hline
\end{tabular}

Fonte: Autor. 


\section{MF' INTERACÃO EM PSICOLOGIA}

Valdivia (2010), ao analisar o relato de 22 atendimentos de Daniel, uma criança de nove anos que sofria com a separação de seus pais desde os seis anos, discute sobre a possibilidade da construção de caminhos criativos para o processo traumático por meio da aplicação de uma psicoterapia breve de orientação psicanalítica auxiliada pelo movimento. Iniciando seus atendimentos pela observação do movimento da criança em sala de aula, o notável desequilíbrio corporal de Daniel poderia representar a desorganização de seu próprio mundo interno, causada pela separação de seus pais, pela internação psiquiátrica de sua mãe, por presenciar o incêndio de sua própria casa e ter que mudar-se para casa de sua avó paterna junto com seu pai, aspectos estes que desencadearam núcleos traumáticos.

Valdivia (2010) propõe e constrói uma relação psicoterapêutica com Daniel capaz de dar conta da revivescência traumática do conteúdo que o levou a adoecer, bem como promove o estabelecimento de um ambiente sustentável visando a contenção de seus sentimentos ambivalentes que, em certo momento, foram direcionados transferencialmente à figura da psicoterapeuta. Para tanto, Valdivia (2010) recorre às teses de Winnicott, da psicoterapeuta Mônica Lanyado, de Laban em seu Movement Analysis (LMA), além das ideias da psiquiatra infantil Judith Kestenberg e o conceito de Movement Profile (KMP).

No final das sessões, após ser alvo do afeto e da hostilidade de Daniel, Valdivia (2010) apresenta o uso de elementos artísticos, do brincar, da criatividade e da dança, como fenômenos transicionais importantes, ao passo que trouxeram à tona o movimento desequilibrado de sua vida psíquica, o qual demandou da psicoterapeuta o estabelecimento de funções maternas e de um ambiente suficientemente bom, capaz de conter as angústias liberadas pelo conflito. Embora Valdivia (2010) aponte os "erros" cometidos no atendimento de Daniel, como, por exemplo, não ter esclarecido inicialmente sobre o período de término das sessões, o que desencadeou em um afastamento agressivo de Daniel da psicoterapia, a autora afirma que após as sessões foi possível construir uma saída "good enough", de modo que a criança pôde revisitar o trauma e ressignificá-lo.

O caso de Daniel expôs o uso da dança e das expressões artísticas, tomando como ponto inicial o processo psicoterápico. No mesmo sentido, podemos encontrar terapêuticas sendo desenvolvidas a partir da dança, como método de intervenção, articulando os saberes do campo da Psicologia e da Psicanálise, ao sentido do movimento no corpo, como, por exemplo, a PMDT. Por meio da junção do saber psicanalítico, da psicodinâmica e da terapia de dança, associações com o enfoque em movimento, terapia e dança, iniciaram a formação de profissionais habilitados a aplicar o método. Segundo o trabalho de Vermes e Incze (2012), a Psychodynamic Movement and Dance Therapy (PMDT) surge na Hungria por volta dos anos 1980, aplicando em 1989 treinamentos para terapeutas da dança, culminando no desenvolvimento dos conceitos e da base metodológica da PMDT.

Vermes e Incze (2012) afirmam que a Movement and Dance Therapy surgiu como uma intervenção em um hospital psiquiátrico para pacientes psicóticos que não respondiam a tratamentos verbais, sua principal expoente foi a psiquiatra Márta Merényi. 0 método proposto pela médica, desenvolveu- se a partir de suas experiências clínicas, da dança contemporânea e do teatro. Sendo credenciada pela Universidade de Semmelweis, a PMTD foi reconhecida pelo conselho de Psicoterapia Húngaro e aceita como um programa metodológico de intervenção psicodinâmico, passando a treinar psicoterapeutas e terapeutas da dança, utilizando-se de técnicas como o Body-Mind e o contato e improvisação. Sendo assim, para Vermes e Incze (2012, p. 102, tradução nossa) o PMDT é um "método psicoterapêutico orientado psicanaliticamente, baseado na eficiência terapêutica do body-work, improvisação do movimento e um trabalho psicodinâmico de experiências de movimento e relações no grupo"1. Ainda segundo os autores, o método trata-se de uma forma criativa para o aprimoramento do desempenho pessoal e autoconsciência, sendo indicado para casos pré-verbais, problemas neuróticos e de reorganização do self. Tecnicamente, as sessões são organizadas em grupo, de 8 a 16 pessoas, ou mesmo individual, sob a coordenação de dois psicoterapeutas, no qual são intercalados períodos verbais, início e fechamento, e não verbais, por meio dos movimentos.

No que tange à psicanálise, as bases que sustentam o método destoam, em certo sentido, dos pressupostos freudianos e aproximam-se das ideias de Ferenczi e Balint no que concerne à ênfase nas precoces relações objetais, com o reconhecimento do "aqui e agora", além da importância da regressão terapêutica (benigna ou maligna), da ação psicanalítica ativa e contato corporal ocasional e reconhecimento da contratransferência (Vermes \& Incze, 2012). Dessa forma, tomando o "amor primário", umas das teses centrais de Balint, como fundo conceitual do método, a técnica psicoterapia do movimento utiliza o toque corporal, em seus sentidos diversos, como uma restauração do amor primário em pacientes acometidos por doenças graves, pois uma "falha básica", ou mesmo uma ruptura, os privou de satisfazer sua base instintual em período inicial verbal de sua vida.

\footnotetext{
1 "psychoanalytically oriented psychotherapeutic method, based on the therapeutic efficiency of body-work, movement improvisation and a psychodynamic working through of movement experiences and relations in the group".
} 


\section{M." INTERACÃO EM PSICOLOGIA}

a terapia atinge o estágio, quando a falha básica entra em foco, a sensibilidade do terapeuta à atmosfera da relação terapêutica ou às expressões corporais do paciente pode assumir uma importância especial e, nesses casos, o toque físico pode se tornar aceitável na situação terapêutica (Vermes e Incze, 2012, p.104, tradução nossa) ${ }^{2}$.

Nesse sentido, ao chegar ao foco da ruptura do "amor primário", a psicoterapia assume um espaço sensível para as expressões corporais do paciente, tendo o toque físico uma aceitação viável na situação terapêutica, pois "as fantasias de um toque podem ser muito mais sexualizadas do que o próprio toque real"3 (Vermes \& Incze, 2012, p. 104, tradução nossa). Dessa forma, a PMDT utiliza-se do aporte de regressão benigna de Balint, a qual não viabiliza uma dependência no paciente ao vivenciar o toque, mas sim em criar um espaço de grupo afetivo que se assemelhe à primeira infância, quando a sintonia com o ambiente tomou uma importância central na comunicação e na existência (Vermes \& Incze, 2012). Nesse contexto, a criatividade surge no intenso trabalho de Body-Mind e nas complexas formas de movimento e improvisação. No "espaço destacado", algo semelhante ao palco, favorece-se improvisações criativas carregadas de sentidos e de manifestações de materiais inconscientes, ao qual é submetido à interpretação pelos membros do grupo e pelos líderes (Vermes \& Incze, 2012).

De modo parecido com a metodologia apresentada por Vermes e Incze (2012), no que tange ao favorecimento de uma situação primeva no processo terapêutico com o recurso da dança, o trabalho de Castanho (2017) discute a utilização da dança circular, ou danças sagradas, como instrumento mediador terapêutico de grupo. Castanho (2017) fundamenta sua discussão nos pressupostos psicanalíticos de J. Bleger e Rene Kaës e evoca os conceitos de sociabilidade sincrética e isomorfismo para dar contornos à intervenção terapêutica que favorece a identificação do espaço psíquico individual com o espaço psicológico coletivo. Após a dança, os membros do grupo são convidados a se reunir para partilhar livremente (associação livre) de sua experiência com a dança e os elementos psíquicos que emergiram. Nessa intervenção, a clivagem da dinâmica sincrética partilhada em grupo (isomorfismo) remonta à relação eu-não eu e conduz o Eu a transformações que promovem uma ressignificação.

Como vimos, o enlaçamento da criatividade, da dança e psicanálise pode ser encontrado e compreendido, no que se refere ao trabalho psicoterápico, seja em grupo ou individual, como formas viáveis e contemporâneas de intervenção ao sofrimento psíquico humano, tomando o corpo, as manifestações expressivas, o inconsciente e a psicologia do ego como acesso à subjetividade humana. Dançar e mover-se tomam características analíticas, enquanto o toque corporal, seja individual ou com o auxílio do outro, ganham espaço na relação psicoterapêutica, sendo articulado a instâncias pré-edípicas, ao contato com o amor primário e a regressão benigna.

\section{CRIATIVIDADE, DANÇA E DINÂMICA PSÍQUICA}

Imbricada com a dinâmica do funcionamento psíquico, a dança e a criatividade podem tornar-se instrumentos capazes de desvelar os caminhos da vida mental, sendo articulados aos conceitos psicanalíticos. Nesse sentido, é possível submeter os processos criativos encontrados na dança, em suas várias faces, à compreensão do arsenal de conceitos produzidos, nesse caso, por Freud, Bion e Heinz Kohut, elencados especificamente nos trabalhos de Wexler (2018), Delgado (2015), Press (2009), Warner (2016), Diamond (2016) e Acciardi (2012).

Sendo assim, o trabalho de Wexler (2018) propõe que a estética artística da dança pode dar contorno ao indizível, tanto do bailarino quanto para a plateia que o observa. Para Wexler (2018), efeitos similares podem ser identificados em uma relação terapêutica de ressonância, em um processo de criação de uma linguagem capaz de organizar os elementos psíquicos e torná-los esteticamente agradáveis. Dessa forma, a dimensão estética tomada no funcionamento da mente, por meio das internalizações realizadas no processo analítico e suas ressonâncias e reorganizações psíquicas, consiste em um trabalho realizado em "par", no qual espera-se que o terapeuta aprenda, em seus atendimentos, a trabalhar com cada paciente à medida que este o ensine o caminho. Trata-se, portanto, de um processo criativo, "no intenso trabalho terapêutico você se envolve com outra mente na busca do dinamismo, da linguagem e do efeito que ressoam mutuamente" ${ }^{4}$ (Wexler, 2018 , p. 208, tradução nossa). Embora nos apropriamos da teoria como mapa e diretrizes gerais de se formar hipóteses quanto ao funcionamento da psique e dos caminhos do sintoma, pode ser encontrado no andamento da psicoterapia um caminhar diferente, forjado na relação de tentativa e erro, de modo a favorecer o processo criativo e a aplicação de algo novo. Assim "quando nossa criação mútua promove um senso de ressonância e expande a capacidade emocional e cognitiva, nossas mentes se reorganizam, de modo que podemos

\footnotetext{
2 "When the therapy reaches the stage, when the basic fault gets in focus, the therapist's sensitivity to the atmosphere of therapeutic relationship or to the patient's bodily expressions may assume special importance, and in such cases physical touch can become acceptable in the therapeutic situation".

3 "the phantasies of a touch may be much more sexualised than the real touch itself".

4 "in intense therapeutic work you engage with another mind searching for the dynamism of mutually resonating language and affect".
} 


\section{M." INTERACÃO EM PSICOLOGIA}

ver o passado e o presente de maneiras que antes nos eram fechadas"5 (Wexler, 2018, p. 208, tradução nossa).

Tomando o Ego, tal qual como apresentado pela teoria freudiana, como uma instância psíquica e como um aparelho de superfície corporal, Wexler (2018) defende que as sensações e percepções perpassam, inicialmente, os sentidos corporais, originando-se no corpo, antes que possam ser decifradas como emoções ou levadas à compreensão racional. É nesse sentido que a arte se insere. As produções artísticas se fazem presente como uma, oferecendo uma percepção corporal e emocional que condiz com uma reflexão e comunicação. Wexler (2018) defende, pautado nas ideias da psicanalista e psiquiatra Ella Freeman, que as percepções e sensações de natureza interna e externa do indivíduo se comunicam, de início, pelo corpo antes mesmo que a própria representação da palavra possa se dar. Nesse contexto, busca-se, no paciente, as associações ligadas ao corpo e seus respectivos significados.

Wexler (2018) ao propor a percepção física dada às associações de conteúdos psíquicos, recorre a sua própria experiência como bailarina, anterior a sua atuação como para aclarar a experiência de desvelar os caminhos de seu sofrimento por meio da dança. Em sua história, Wexler (2018) conta que quando tinha 12 anos foi enviada para um acampamento no qual assistiu, em uma noite de talentos, o solo de dança de Rachel, a conselheira do acampamento. Nele, presenciou a expressão estética física dos sentimentos da bailarina, manifestando na dança sua "escuridão". A experiência com a dança de Rachel levou Wexler (2018, p. 209, tradução nossa), no término da noite, a refletir sobre seus próprios processos individuais e seus sofrimentos, "eu corri do salão de recreação para a noite fria e permiti que minha própria tempestade quebrasse o calor brutal e sufocante daquele verão"6. A dança de Rachel, favoreceu a identificação e permitiu um caminho expressivo para o representar de angústias em uma linguagem não verbal, no qual o movimento reverberou em seu próprio corpo, como metáforas que davam sentido a seu sofrimento emocional (Wexler, 2018). No final de sua experiência no acampamento, a autora buscou na dança controle e precisão do corpo para que tivesse condições de articulá-las a movimentos repletos de sentidos e metáforas expressivas, "que contivesse e organizassem meu sofrimento" ${ }^{7}$ (Wexler, 2018, p. 209, tradução nossa).
Raphael Edson Dutra e Maíra Bonafé Sei
Rememorando sua própria experiência pessoal com a dança e a reorganização de sua vida emocional na psicoterapia, Wexler (2018, p. 211, tradução nossa) afirma que os efeitos da psicoterapia passam, portanto, a serem percebidos, como na dança, por metáforas que podem ressoar os processos internos, ressignificando-os, e conclui:

Quando o terapeuta e o paciente participam, um processo terapêutico se dá e o paciente absorve a beleza, o prazer e a capacidade criativa de confiar e ressoar com seus próprios processos internos; confiar nos sentimentos corporais como autocomunicações convincentes, valorizar pensamentos até absurdos, saborear fragmentos de música, poesia e cinema à medida que vêm à mente, e notar que impulsos em certas direções têm ritmos e significados que revisam, informam e renovam antigas suposições. É essa ressonância, fluidez, dinamismo e transformação que tornam a terapia e a análise uma arte performática ${ }^{8}$.

Conforme demonstrou o trabalho e a experiência de Wexler (2018), a ressonância dos processos psicoterapêuticos e os encontrados no corpo e dança apresentam-se como metáforas que visam reorganizar a dinâmica psíquica por meio de processos criativos. Compreensão semelhante, em hipótese, pode ser encontrada no trabalho de Delgado (2015), o qual parece-nos aclarar uma possível forma de compreender o funcionamento do processo criativo e da reorganização dos conteúdos psíquicos elegendo as teorizações de Bion como pressupostos norteadores. Segundo Delgado (2015), Bion remeteu-se às ideias de Poincaré para designar o conceito de facto selecionado, o qual refere-se às instâncias responsáveis pela criatividade, nesse caso, científica.

Dessa forma, a criatividade para Bion pode estar imbricada na relação da posição esquizo-paranoide (SP) e da posição depressiva (D). Para Delgado (2015, p. 155), a teoria bioniana entende esse processo como um afrouxamento da integração das ideias, "envolve o desmoronamento de opiniões e teorias anteriores, com o desenvolvimento de novas opiniões e teorias", em um constante processo de dissolução, uma desordem conhecida como posição esquizo-paranoide. Porém, aponta Delgado (2015), o afrouxamento da posição esquizo-paranoide encontra um ponto de união na posição depressiva (D) e, consequentemente, ocorre a reformulação e organização dos fragmentos em algo novo, em um processo

\footnotetext{
5 "when our mutual creation furthers a sense of resonance and expanding emotional and cognitive capacity, our minds reorganize, so that we can view the past and present in ways that were closed to us before".

6 "I ran from the recreation hall into the cool evening and allowed my own storm to crack that summer's brutal and suffocating heat [...]".

7 "that contained and organized my despair".

${ }^{8}$ "When therapist and patient part, a therapeutic process continues if the patient has taken in the beauty, pleasure, and creative capacity to trust and resonate with his/her own internal processes; to trust body feelings as convincing self-communications, to value even absurd thoughts, to savor fragments of song, music, poetry, film as they come to mind, and to note that urges to move in certain ways have rhythms and meaning that review, inform, and renew old assumptions. It is this resonance, fluidity, dynamism, and transformation that make therapy and analysis a generative, performing art".
} 


\section{MLE INTERACÃO EM PSICOLOGIA}

criativo. Esse "ciclo" do encontro entre as posições sintetizam um movimento da reformulação de teorias e criação de novas ideias e, conforme aponta Delgado (2015, pp. 155-156), de processos artísticos. Com isso, "o esforço criativo pode assim ser encarado como um processo, em pequena escala, de movimentos para lá e para cá entre a posição esquizo-paranoide e a posição depressiva".

Embora Bion aponte o curso do funcionamento do processo criativo no âmbito científico, Delgado (2015) propõe sua expansão ao articulá-lo com as produções artísticas. Referenciando a dança contemporânea e suas expoentes Martha Graham e Pina Bausch, Delgado (2015, p. 164) encontra na dança um elemento capaz de produzir sentidos e dizer sobre realidades subjetivas do indivíduo, pois "através do corpo em ação na dança que se passa da fisiologia à psicologia, da física à metafísica, da sensação à representação". Dessa forma, a criação na dança moderna pode representar a oscilação entre as posições esquizo-paranoide e depressiva, em um processo criativo, em outros termos, na dança moderna, o gesto encontraria no mover não apenas uma linguagem corporal, mas uma representação metafísica de natureza psicológica (Delgado, 2015).

Deslocando aquilo que é dito pelo corpo na dança e não dito pela fala, de um constructo articular entre as posições esquizo-paranoide e depressiva para as relações objetais e para o self, da psicanálise bioniana para a psicologia do Self de Kohut, podemos compreender a partir do trabalho de Warner (2016) outra dinâmica psíquica que enlaça o processo criativo e a dança, tomando como ponto de partida o conceito de empatia. Em seu trabalho, a autora objetivou comparar sua experiência na prática da clínica psicanalítica e da dinâmica psíquica implicada na relação psicoterapêutica à dança, especificamente para a salsa. Para tanto, Warner (2016) afirma que, para a prática clínica, é preciso que a relação terapêutica se encontre assentada em uma atitude empática com o paciente, conceito este que difere potencialmente no reconhecido pelo senso comum. Empatia, nesse contexto, é tomado como uma posição sensível perante o outro, não atendo-se a julgamentos ou obstinações. Trata-se de tentar ater-se ao mundo do outro dividindo com ele as perspectivas e compreensões tomadas nesse caminho de tal modo a levar o paciente a elaborar, ou mesmo, reiterar as impressões alcançadas.

Para Warner (2016, p. 25, tradução nossa), "experienciar" a perspectiva individual de outrem está presente no arsenal biológico inato da constituição humana, fato este que já fora retratado por artistas e analistas, "somos geneticamente programados para entender as motivações, ações e emoções dos outros" ${ }^{9}$. Transpondo o aspecto genético para a relação psicoterapêutica, a atitude do analista diante de seu paciente decorre de tentar comunicar as percepções obtidas, no corpo inteiro, mediante as histórias do paciente, em uma ligação ressonante afetiva. Segundo Warner (2016), o compromisso empático terapêutico é preciso estar interligado com alguma prática, nesse caso, a arte, a criação e a dança. Trata-se de transcender as impressões superficiais cognitivas, aprofundando-as em direção à cura e trazendo benefícios criativos ao paciente e para o próprio analista.

Warner (2016) afırma que a arte pode ser vista não apenas como um processo regenerativo das experiências humanas, mas também contém aspectos potencialmente constitutivos que visam aprimorar a capacidade empática em diversos setores, como: No contato direto com o outro, compreendendo e expressando elementos do self que poderiam ser desconhecidos; Na aplicação de um modelo de exploração do mundo interno e manifesto do outro; No fornecimento de uma ferramenta de autorrealização, aprimorando das funções de "Selfobjecto" na relação analítica. É nesse ínterim que Warner (2016, p. 28, tradução nossa) elege sua experiência como dançarina de salsa e admite que a dança e a psicoterapia psicanalítica dialogam, pois "aprende a perceber e interpretar até mesmo os gestos mais sutis do corpo do parceiro, para fazer uso e expandir as capacidades biológicas inatas"10. Dessa forma, a dança de salsa e psicoterapia apresentam elementos semelhantes que lhe são implícitos. Nesse sentido, na salsa, encontra-se a dinâmica de liderança, ritmização, atenção aos batimentos cardíacos e a permissão de condução pelo guiador, já no funcionamento psíquico, estes aspectos ressoam como "uma bela metáfora para uma transferência produtiva das relações objetais que permite ao analista entrar no mundo do paciente"11 (Waner, 2016, p. 28, tradução nossa).

Análoga à perspectiva de Warner (2016), Press (2009) propôs integrar as experiências de coreógrafos modernos e a dinâmica da criatividade. Ao investigar essas percepções, entendeu que o movimento surge e tem seu núcleo na sensação e na função das relações objetais no qual, por meio da empatia, o coreógrafo é levado a criar a experiência da estética, fundada no desenvolvimento de suas sensações passadas e em sua própria historicidade. As produções artísticas e a dança levariam o artista a conectar-se com suas necessidades profundas, utilizando como ferramenta a empatia, afırmação, exploração, vitalidade e momento atual (Press, 2009). Nesse

\footnotetext{
9 "we are genetically programmed to understand the motivations, actions, and emotions of others".

10 "learning to perceive and interpret even the subtlest gestures of the partner's body, to make use of and expand upon innate biological capacities".

11 "[...] a beautiful metaphor for the clicking-in of a productive selfobject transference that allows the analyst into the patient's world".
} 


\section{M." INTERACÃO EM 2 PSICOLOGIA}

sentido, o coreógrafo-dançarino estabelece um relacionamento autoempático, criando o movimento e ilustrando as relações intersubjetivas que podem decorrer de si mesmo e do meio, pois "para o dançarino, o movimento e a criação de uma forma externa - a obra de arte - servem as funções vitais do selfobjeto"12 (Press, 2009, p. 223, tradução nossa). Quando cria, o coreógrafo atenta-se para o seu corpo e para a sensação, visando explorar elementos sensoriais potencialmente relevantes (Press, 2009).

A criação coreográfica e artística também se torna alvo a ser analisado no trabalho de Diamond (2016). Tomando uma produção cinematográfica, "The Red Shoes", como objeto de investigação, a autora propõe interpretar as relações inconscientes presentes no enredo e no ballet que o compõem, como em um sonho dentro de um sonho, tomando a teoria freudiana como eixo central. Nele, uma aspirante a bailarina clássica é convidada por um empresário a dançar uma produção que tem como centro um par de sapatilhas de ponta enfeitiçadas da cor vermelha. Resumidamente, a bailarina incitada pelo estranho sapateiro coloca-as em seus pés e se inicia uma frenética dança contínua, que transpassa por diversos cenários, até o fim trágico, com um desejo de amputar seus próprios pés e a própria morte. Na perspectiva de Diamond (2016), o filme pode relatar os conflitos inconscientes e compulsórios da personagem, como também expressa as vorazes artimanhas da pulsão de morte. 0 enredo se completa com o drama edipiano vivenciado pela bailarina, por seu amante e rival (o músico contratado para compor o ballet), e o próprio empresário que a contempla em processos sublimatórios e narcísicos (Diamond, 2016).

Diamond (2016. p. 109, tradução nossa) afırma que a história presente no ballet, circunscreve o drama em uma representação de uma sexualidade transgressora, o desejo pela criatividade e os limites e alcances agressivos da pulsão de morte e vida, no qual a personagem central defronta-se conflituosamente com "seu eu criativo que celebra a arte da dança; seu eu erótico que se deleita na dança exibicionista de desejar e ser desejado" ${ }^{13}$. Aspectos do anseio homossexual do empresário, que encontram caminhos sublimatórios nos significantes femininos, também são analisados como pertencentes a triangulação edipiana. Decerto, o trabalho de Diamond (2016) apresenta elementos importantes para a compreensão da dinâmica psíquica imbricada na personagem, de modo que a dança e seu corpo se tornam palcos de conflitos internos, acentuando aspectos narcísicos, fálicos e submissos em meio às exigências da compulsão à repetição (Diamond, 2016).
Raphael Edson Dutra e Maíra Bonafé Sei
O dançar frenético liderado pela compulsão à repetição da bailarina apresentada no filme, e analisada por Diamond (2016), faz-nos lembrar do trabalho de Alves (2009), o qual retoma a ideia de Freud sobre a compulsão à repetição para se referir à retroalimentação inesgotável da angústia do bailarino no processo criativo. Sendo assim, Alves (2009) elege a dança como uma possível representante da pulsão e do afeto e, como tal, está sujeita aos processos característicos da demanda pulsional, elemento este compreendido como uma angústia no processo criativo (Alves, 2009). A dança, assim, é tomada em um circuito do desejo, do desejante, o que leva o dançarino a não se contentar com apenas uma dança, mas "cada dança alimenta a vontade de mais dança, de mais movimento" (Alves, 2009, p. 347). As imagens representadas por gestos são tomadas como linguagem que atravessam o corpo e subvertem a consciência em processos projetivos, fazendo "referência a algo que pulsa dentro do corpo e que se mobiliza em direção a uma descarga através da dança" (Alves, 2009, p. 347).

Na perspectiva de Alves (2009, p. 348), a angústia apresenta-se na criação em dança, ao passo que o representante pulsional não consegue suprir a falta, a insuficiência, da satisfação da pulsão, atraindo o aperto angustiado do processo criativo, "está injunção mantém intocável o desejo, e alimenta o processo criativo, na medida em que o criador é afetado por esta angústia cortante". Mediante a experiência criativa, o sentimento angustiante surge ao eclodir de uma sensação de estranheza, pela imersão do conteúdo inconsciente. 0 estranho, por sua vez, "retorna, inapreensível, pois nenhuma representação o subjuga, caracterizando-se aí a constância da pulsão" (Alves, 2009, p. 348). Para o autor, a criação é retroalimentada pelo retorno do estranho e em sua tentativa de representação gestual, e pela angústia de conseguir ater-se às necessidades do inconsciente. $\mathrm{Na}$ dança e na criação, o movimento tornar-se-ia a repetir-se procurando se expressar em uma constante sensação de insuficiência (Alves, 2009). Em seu grau psicopatológico, a repetição do indizível, iludida no movimento, pode clivar as partes integradas da criação e dos significados como nos mostrou Acciardi (2012) em relação ao dançarino russo Vaslav Nijinsky, acometido pela esquizofrenia e episódios maníacos. Nesse caso, o bailarino sentia seu corpo invadido por um gozo incontrolável, no sentido lacaniano, levando-o a recorrer a normas fálicas e sistemas simbólicos que fracassadamente tentavam dar "razão" a seus movimentos (Acciardi, 2012). Vaslav Nijinsky, semelhante ao paciente Schreber de Freud, acreditava que ao dançar no

\footnotetext{
12 "for the dancer, movement and the creation of an external form the art work serve vital selfobject functions".

13 "her creative self that celebrates the artistry of dance; her erotic self that revels in the exhibitionistic dance of desiring and being desired [...]".
} 


\section{MTERAC̄OAEM PSICOLOGIA}

palco "não seria ele, senão Deus, quem o move enquanto está em cena" 14 (Acciardi, 2012, p. 32, tradução nossa).

Por fım, dançar, movimentar-se e criar parecem estabelecer possibilidades criativas de compreender a dinâmica imbricada nos processos psíquicos que lhe são subjacentes. Articulado ao corpo, representação pulsional, as experiências do self, as relações objetais, a empatia, o ambiente e processos psicopatológicos, dança e criatividade parecem encontrar representantes gestuais que procuram se satisfazer e se comunicar por meio de uma linguagem própria, regida pelo desvelar de instâncias e determinações inconscientes.

\section{CONSIDERAÇÕES FINAIS}

A dança é uma expressão, uma habilidade corporal, capaz de traduzir para uma linguagem um enredo gestual complexo, que se apoia na vida psíquica e emocional humana. Por meio da dança, elementos como a criatividade entram em cena e compõem uma "coreografia" que, ao se apresentar ao público, e ao próprio bailarino-criador, refere-se a uma interlocução arranjada entre corpo e inconsciente. Investigar o processo de criação em dança consiste em compreender os elos de ligação que se inscrevem para além do movimento, no qual a estética artística está a serviço do desejo e ao jogo de forças que lhe são subjacentes.

Nesse contexto, a presente pesquisa visou ater-se às produções publicadas em periódicos indexados que, de alguma forma, tratavam sobre a temática tomando a psicanálise como referencial teórico para a construção de análises. Nessa busca, foram encontrados artigos que, após serem aglomerados em eixos temáticos, contribuíram para a identificação do estado pelo qual o tema é tratado no meio acadêmico. Assim, percebeu-se que a dança pode, ao ser tomada como recurso terapêutico, atuar no sentido de favorecer a manifestação criativa de caminhos alternativos para a demanda interna do paciente. Como aporte metodológico, a dança pode embasar-se na psicanálise e construir uma estratégia de intervenção própria, na qual o sentir, o corpo, o movimento e a fala manifestam uma livre expressão criativa, tornando-se um recurso na clínica da escuta psicanalítica.

De certo, a dinâmica psíquica imbricada na criação em dança pode ser compreendida desde um processo integrativo entre o circuito das posições esquizo-paranoide e depressiva, como também uma representação pulsional engendrada na compulsão à repetição. Da psicologia do self, e seu conceito fundamental da empática, à psicanálise, por meio de autores de língua inglesa e francesa, podemos concluir que o proces- so criativo em dança ressoa ao ser como uma necessidade, um "impulso" criativo, que visa se comunicar por meio de uma linguagem gestual, corporal, mas também inconsciente.

Embora a criatividade seja alvo de investigação na psicanálise tornando-se conceito-chave de teorias psicanalíticas, como a de D. Winnicott, sua interlocução com a prática artística da dança, em suas diferentes modalidades, ainda é pouco produzida. Nesse sentido, pôde-se observar, por meio deste trabalho, a baixa produção acadêmica tomando a criação na dança como alvo de estudo. Nesse sentido, aponta-se para a pertinência de pesquisas futuras acerca dessa temática, contribuindo para a produção de conhecimento tanto no campo psicanalítico como na dança.

\section{DECLARAÇÃO DE CONFLITOS DE INTERESSES}

Os autores declaram que não há conflitos de interesses no presente artigo.

\section{REFERÊNCIAS}

Acciardi, M. (2012). Vaslav Nijinsky, una mirada psicoanalítica sobre su arte y su locura. Revista Universitaria de Psicoanálisis, 12, 291-311.

Alves, F. S. (2009). A dança "en-cena" o Outro: prerrogativas para uma educação estética através do processo criativo. Movimento (ESEF/UFRGS), 15(3), 333-354. https://doi. org/10.22456/1982-8918.5391

Campos, M. N. M. (2011). Narrativas do corpo. Revista Brasileira de Psicanálise, 45(4), 25-28.

Castanho, P. (2017). Um olhar psicanalítico sobre o uso das danças circulares como instrumento de trabalho com grupos. VÍNCULO, 14(2), 70-83.

Costa, A. B.; Zoltowski, A. P. C. (2014). Como escrever um artigo de revisão sistemática. In: Koller, S. H.; Couto; M. C. P.; Hohendorff, J. V. (orgs.) Manual de Produção Científica (pp. 55-70). Penso.

Delgado, L. (2015). O balanceamento entre as posições esquizo-paranoide e depressiva ( $P s \leftrightarrow d)$ na psicodinâmica criativa. Tempo Psicanalítico, 47(1), 154-166.

Diamond, D. (2016). The Red Shoes: A Fairy Tale Within a Ballet Within a Film. American Psychological Association, 33(Suppl 1), S104-S119. https://doi.org/10.1037/ pap0000071.sup

Galvão, T. F., \& Pereira, M. G. (2014). Revisões sistemáticas da literatura: passos para sua elaboração. Epidemiologia e Serviços de Saúde, 23(1), 183-184. https://doi. org/10.5123/S1679-49742014000100018

14 “[...] no sería él sino Dios quien lo mueve cuando está en escena”. 


\section{MF" INTERACÃO EM ET. PSICOLOGIA}

Press, C. M. (2009). Self psychology and the modern dance choreographer. Annals of the New York Academy of Sciences, 1159 (1), 218-228. https://doi.org/10.1111/j. 1749-6632.2009.04354.x

Sampaio, R., \& Mancini, M. (2007). Estudos de revisão sistemática: um guia para síntese criteriosa da evidência científica. Revista Brasileira de Fisioterapia, 11(1), 83-89. https://doi.org/10.1590/S1413-35552007000100013

Valdivia, M. E. (2010). A psychoanalytic perspective of endings in therapy: A dance movement psychotherapy case study. Body, Movement and Dance in Psychotherapy, 5(1), 75-87. https://doi.org/10.1080/17432971003593971

Vermes, K., \& Incze, A. (2012). Psychodynamic Movement and Dance Therapy (PMDT) in Hungary. Body, Movement and Dance in Psychotherapy, 7(2), 101-113. https://doi.org/10 $.1080 / 17432979.2011 .557890$
Victoriano, J. D. (2011). O Corpo em Cena: Algumas considerações sobre a entrevista de Inês Bogéa. Revista Brasileira de Psicanálise, 45(4), 29-32.

Warner, A. (2016). Listening to All of You with All of Me: The Arts, Empathy, and the Analyst. Smith College Studies in Social Work, 86(1), 24-34. https://doi.org/10.1080/00377 317.2015.1114770

Wexler, J. (2018). Therapeutic action and aesthetic experience: Resonance and reorganization. Journal of Clinical Psychology, 74(2), 208-212. https://doi.org/10.1002/jclp.22575

Winnicott, D. (1975). O Brincar e a Realidade. Imago Editora.

Artigo recebido em: 06/09/2018 Ultimas modificações: 09/04/2019 Artigo aceito em: 20/04/2019 